\title{
OBSERVAÇÃO DE AVES E ATIVIDADES LUUDICAS NO ENSINO DE CIÊNCIAS E EDUCAÇÃO AMBIENTAL NO PANTANAL (MS)
}

\author{
Mayra Lopes Nogueira ${ }^{1}$ \\ Eliane Mattos Piranda ${ }^{2}$ \\ Maristela Benites da Silva ${ }^{3}$ \\ lêda Maria Novaes Ilha ${ }^{4}$ \\ Natália Aguiar Paludetto ${ }^{5}$ \\ Valquíria Araújo Benites ${ }^{6}$
}

Resumo: O presente trabalho objetivou aliar educação ambiental e ensino de ciências utilizando as aves pantaneiras como tema para elaboração de atividades didático-pedagógicas. Mensalmente foram desenvolvidas vivências em campo para observação de aves e atividades lúdicas que integraram educação ambiental e ciências. Um questionário semiestruturado sobre o tema foi respondido por 20 alunos e analisado de forma qualitativa e quantitativa. As atividades lúdicas compreenderam estórias, jogos e atividades de pintura que possibilitaram reconhecimento da biodiversidade, respeito e sensibilidade com o meio ambiente. Houve maior detalhamento em todas as respostas pósintervenções e o número de espécies de aves mencionadas pelos alunos antes e depois do projeto diferiu significativamente. As atividades demonstraram ser um eficiente instrumento de ensino de ciências e educação ambiental.

Palavras-chave: Avifauna; Pantanal; Educação.

\footnotetext{
${ }^{1}$ Universidade Federal de Mato Grosso do Sul. E-mail: mayra_In@hotmail.com.

2 Universidade Federal de Mato Grosso do Sul. E-mail: E-mail: eliane.piranda@ufms.br.

${ }^{3}$ Instituto Mamede. E-mail: maris.benites@gmail.com.

${ }^{4}$ Universidade Federal de Mato Grosso do Sul. E-mail: iedailha@gmail.com.

${ }^{5}$ Universidade Federal de Mato Grosso do Sul. E-mail: nataliaapaludetto@gmail.com.

${ }^{6}$ Universidade Federal de Mato Grosso do Sul. E-mail: valquiriac09@hotmail.com.
} 


\section{Introdução}

O Brasil é o principal país dentre os mais megadiversos do mundo, o que significa dizer que apresenta maior biodiversidade do planeta, com exuberante riqueza de fauna e flora, resultado de sua localização geográfica, da variedade de zonas biogeográficas distintas e de seus espaços climáticogeomorfológicos que proporcionam biota e ecossistemas igualmente diversos, favorecendo a sobrevivência e cerca de $20 \%$ do número total de espécies no mundo (SICK, 1997; MMA, 2013). De acordo com o Comitê Brasileiro de Registros Ornitológicos (CBRO, 2014), são registradas 1.901 espécies de aves no Brasil das 9.900 espécies de aves distribuídas no mundo (MMA, 2013).

As aves têm se tornado tema de investigação cada vez mais frequente, sendo o nosso país de destaque dentre os que apresentam maior número de aves do planeta; no entanto, várias espécies correm risco de desaparecer em futuro próximo em decorrência da fragmentação e perda de seu hábitat natural, fazendo-se necessárias investigações para a aplicação de estratégias conservacionistas em favor de sua proteção e valorização (ALVES et al., 2000; MARINI; GARCIA, 2005; SILVA; MAMEDE, 2008). No contexto da avifauna brasileira, tem-se o Pantanal, bioma que apresenta cerca de 580 espécies de aves, 23 das quais ameaçadas de extinção em âmbito global e nacional (NUNES, 2010; 2011). O Pantanal é considerado referência mundial quanto ao turismo de observação de vida silvestre, onde vários grupos biológicos, como 0 das aves, atuam como elementos de forte atração turística contribuindo para agregação valorativa à biodiversidade.

Desde tempos remotos as aves são admiradas pelo homem em virtude de suas formas, cores, cantos e modo de vida, acompanhando-o, seja na forma de inspiração artística, para consumo alimentar, controle de pragas, uso das penas, para estudos técnico-científicos, no turismo, dentre outras formas de uso (ARGEL-DE-OLIVEIRA, 1997; SICK, 1997; SILVA; MAMEDE, 2008). São vertebrados cobertos por penas, as quais garantem a força de ascensão e o contorno aerodinâmico para 0 voo, além de serem responsáveis pelo isolamento térmico, bem como são consideradas indicadoras de qualidade ambiental (POUGH et al., 2008; SICK, 1997). Esses animais podem ser encontrados em todos os continentes, desde ambientes rurais até os centros urbanos, muito embora, neste caso, sejam menos diversas, devido à movimentação e ruído de carros, pessoas, poluição atmosférica e falta de vegetação nativa que restringem a oferta de condições e recursos favoráveis a sua sobrevivência. Por todas essas características, as aves podem servir, ao mesmo tempo, como instrumento de sensibilização e reconexão do ser humano ao mundo natural enquanto ferramenta útil ao ensino de ciências.

As práticas de ensino, bem como as metodologias utilizadas pelos profissionais de ensino, sejam elas participativa, colaborativa, construtivista, e, os conhecimentos popular e científico adquiridos pelos alunos, serão sempre subsídios importantes para trabalhar e fundamentar a educação. E, no que tange à educação, parte-se do pressuposto que o resultado a ser esperado é 
uma mudança de pensamentos e ações, traduzidos em transformação social, com indivíduos críticos, autônomos e de postura ética (FREIRE, 1996; AMORIM, 2005).

Freire $(1996,1981)$ argumenta que ensinar não é simplesmente transferir conhecimento, mas criar as possibilidades para a sua produção ou construção, associando ação e reflexão, homem e sua realidade, de modo a garantir seres de compromisso com o mundo, com a natureza, com a sociedade. Então, trazer para dentro da sala de aula a realidade dos alunos por meio de metodologias diferenciadas, é favorecer a própria educação em sua essência.

Conforme a Política Nacional de Educação Ambiental (1999), no âmbito escolar, a educação ambiental, denominada formal, tem que ter um enfoque global e integrado, contínuo e permanente em todos os níveis e modalidades do ensino formal, não restritiva a uma única disciplina escolar. Dessa forma, faz-se necessário o desenvolvimento contínuo de diferentes modalidades básicas de educação ambiental no Brasil, por meio de projetos, disciplinas especiais ou inserção de uma temática ambiental nas disciplinas (BRASIL, 2013). De acordo com Krasilchik (2008), trabalhos de ensino de ciências fora da sala de aula objetivam, dentre outros aspectos, desenvolver a percepção e aumentar a interação professor-aluno.

Torna-se, assim, um grande desafio para os educadores relacionar educação e meio ambiente que culmine na formação de cidadãos conscientes, comprometidos com a vida e com a transformação da sociedade. Cabendo, portanto, aos educadores, garantir situações socioambientais e práticas educativas que possibilitem aos educandos agir e atuar de forma transformadora na sociedade e no ambiente como um todo. Dessa forma, fazse necessário estabelecer relações entre casa e escola, dois universos distintos que deveriam ser unidos pela educação (BRASIL, 1998).

Essa forma de pensar e agir é corroborada pela educação ambiental crítica e transformadora, enfatizada neste trabalho, que consiste em romper com a educação tecnicista focada apenas em repassar o conhecimento o tempo todo, se transformando em uma educação que incide sobre as ações e por consequência na vida dos sujeitos, compreendendo as relações que envolvem a sociedade para com a natureza, intervindo sobre os problemas de forma crítica, estabelecendo valores e atitudes conforme a ética ambiental, social e contribuindo para uma nova identidade como sujeito ecológico (MMA, 2004; SATO; CARVALHO, 2005).

Planejar estratégias de educação ambiental por meio dos materiais didáticos representa uma das inúmeras possibilidades para se desenvolver ações que sensibilizem alunos, comunidades e populações em geral, sobre as preocupações relacionadas à crise social que tem comprometido, ao longo dos anos, a fonte dos recursos naturais. Desta forma, buscam-se como medidas 
estratégicas para conservação realmente efetiva, a implementação de métodos práticos e pedagógicos de educação ambiental (SILVA; MAMEDE, 2008).

Ainda que fosse possível trabalhar a avifauna do Pantanal apenas no contexto do ensino de ciências, o estudo ora apresentado se propôs a unir ensino de ciências à educação ambiental utilizando as aves como tema central, uma vez que privilegiando somente o primeiro poder-se-ia restringir demais à apreensão de conhecimento no âmbito técnico-científico, priorizando apenas o campo cognitivo do ensino. Já, a educação ambiental pauta-se no comportamento e atitudes dos indivíduos, pode torná-los sujeitos éticos, próativos, reflexivos e responsáveis com mundo e com a transformação da sociedade. Dessa forma, o elo proporcionado pela temática aves teve 0 propósito de estimular e habilitar sujeitos cognoscentes no que tange ao ensino de ciências, concomitantemente à formação de sujeitos sensíveis, afetuosos, autocríticos e com autoestima, conectados ao meio, capazes de mudar a realidade socioambiental e valorizar a biodiversidade local com a qual interagem cotidianamente.

Dessa forma, o trabalho objetivou aliar ensino de ciências à educação ambiental utilizando como instrumento didático-pedagógico as observações em campo, estórias, jogos lúdicos, relacionadas às aves que ocorrem no Pantanal Sul-mato-grossense, estratégia adotada também, para acessibilizar e disseminar resultados de pesquisas científicas à comunidade local.

\section{Procedimentos metodológicos}

\section{Caracterização da área de estudo}

O projeto de pesquisa foi realizado em uma escola da rede pública municipal de Corumbá (MS): Escola Municipal Rural Luiz de Albuquerque de Melo Pereira e Cáceres e Extensões, instalada na Base de Estudos do Pantanal (BEP), da Universidade Federal de Mato Grosso do Sul (UFMS), unidade de ensino e pesquisa de campo e atividades de extensão.

O trabalho, ora apresentado é parte de um projeto maior que envolve participação social, denominado "Ocorrência e distribuição de passeriformes em campos alagáveis do Pantanal de Mato Grosso do Sul" do Instituto Nacional de Ciência e Tecnologia em Áreas Úmidas (INAU) da UFMS.

As edificações físicas da Base de estudo do Pantanal dispõem-se na área de abrangência da mata ciliar do rio Miranda e o acesso à escola se dá por estradas vicinais e internas de fazendas, hotéis-fazenda e pesqueiros, eventualmente por rio, em época de cheia ou conforme o local de residência do aluno. No Pantanal a abundância faunística é naturalmente alta, não sendo diferente nas imediações da BEP, tanto mais por integrar diferentes unidades de paisagem como rio, mata ciliar, lagoas temporárias, campos, formações vegetais monodominantes (e.g., paratudal e piuval), o que potencializa a 
ocorrência de alta diversidade de aves e outros elementos da biodiversidade local.

Próximo ao refeitório há um comedouro onde, regularmente, são dispostos itens alimentares para as aves, causando admiração das pessoas, mesmo daquelas não habituadas à observação de aves.

\section{Público-alvo da pesquisa}

As atividades foram desenvolvidas com 11 alunos das séries finais do ensino fundamental, com idade entre 11 e 17 anos, após assinatura do termo de consentimento livre e esclarecido, antes submetido e aprovado pelo conselho de ética da UFMS (CEP $\mathrm{n}^{\circ}$. 438.342). De modo geral as atividades foram desenvolvidas com 20 alunos, sendo das séries iniciais e finais do ensino fundamental, 11 desses alunos do $6^{\circ}$ ao $9^{\circ}$ ano responderam ao questionário semiestruturado, porém somente 07 responderam ao questionário antes e depois das intervenções propostas por este trabalho.

Diretamente, foram atingidos todos os alunos da escola, no entanto, sistemática e regularmente, ao longo de 07 meses (entre 2012 e 2013), durante dois a três dias mensais, as atividades se dirigiram a alunos do $6^{\circ}$ ao $9^{\circ}$ ano, em virtude da regularidade curricular da disciplina de ciências. Dado o baixo número de alunos, as aulas são concentradas em uma única sala, denominada multisseriada.

Um questionário semiestruturado foi elaborado e aplicado a cada aluno, a partir do qual, foi avaliado o nível de aproveitamento e aprendizagem antes e depois das intervenções propostas neste trabalho. O questionário abordou conhecimentos fisiológicos, comportamentais e a história natural das aves (habitat, morfologia, alimentação, reprodução, cantos, se vivem em bandos, solitários ou casais) e qual sua importância na natureza; se a vida das aves é comparável a dos humanos, numa tentativa de estimular a reflexão sobre o ser humano enquanto membro da biodiversidade que leva vida em sociedade; quais seriam as atitudes recomendáveis para a proteção das aves, e assim chegar à conservação da natureza em harmonia entre seres humanos e destes com os demais seres vivos. Sucinta avaliação também foi empregada ao final de cada módulo de atividades.

\section{A interação aluno, professor e ambiente: as estórias e os jogos}

Após a aplicação do questionário, foram elaboradas e contadas estórias inéditas com autoria de Mayra Lopes Nogueira e Maristela Benites sobre algumas espécies de aves do Pantanal, sendo este o instrumento aglutinador de todas as demais ações do projeto. Ao total foram trabalhadas oito estórias com as aves do Pantanal, muitas das quais vistas por eles quase diariamente: joão-de-barro (Furnarius rufus), gralha-do-Pantanal (Cyanocorax cyanomelas), 
periquito-de-encontro-amarelo (Brotogeris chiriri), tucano (Ramphastos toco), garça-branca-grande (Ardea alba), arara-azul-grande (Anodorhynchus hyacinthinus), curió (Sporophila angolensis), e caburé (Glaucidium brasilianum). As estórias foram narradas com auxílio de projetor multimídia, sendo também desenvolvidas sob a forma de peças teatrais no pátio da escola, neste caso, à margem do rio Miranda. Como fundo musical para as estórias utilizou-se poesias musicadas sobre aves, meio ambiente e Pantanal (CD Crianceiras por Marcio de Camillo). As mesmas subsidiaram os jogos lúdicos que complementaram os objetivos do trabalho e diversificaram as atividades a partir de outras linguagens.

Os jogos educativos (lúdicos) foram desenvolvidos para promover a interação entre alunos e destes com o professor, para facilitar a memorização dos sons produzidos pelas aves, de cores da plumagem, também para estimular o uso de lógica matemática e da expressão corporal, constituindo-se de jogos cooperativos, individuais e/ou em grupos, todos com ênfase em meio ambiente, biodiversidade e na avifauna do Pantanal, além de vivências em campo. Ao total foram aplicados dez jogos lúdicos descritos a seguir:

1. Jogo da Memória, divididos em quatro subtemas (ninhos, jogo dos casais, dos juvenis e alimentação), cada um com dez pares de peças;

2. Jogo de Encaixe, desenvolvido para as crianças menores, uma vez que, eventualmente, alunos das primeiras séries do ensino fundamental também participavam das atividades. Esse jogo é constituído por cinco cubos, cada um com três encaixes (indivíduo adulto, filhote e ninho), totalizando 15 peças;

3. Jogo de Dama, onde cada peça do jogo consistiu de semente de acuri ou de concha de moluscos abandonada, visto que a parte viva já havia sido consumida por aves como o gavião-caramujeiro (Rostrhamus sociabilis), carão (Aramus guarauna), dentre outras.

4. Jogo da Velha, no qual o tabuleiro traz a representação de duas espécies de aves e as peças do jogo também se constituem de conchas de moluscos do gênero Marisa.

5. Jogo de Dicas, no qual foram escolhidas várias espécies de aves, sendo cada espécie com três dicas, para que os alunos a identificassem. Os que acertassem na primeira dica recebiam quinze pontos, na segunda, dez pontos e na terceira cinco pontos. Foi nomeado vencedor o grupo de alunos que tinha maior quantidade de pontos.

6. Jogo de Dominó, cujas peças foram feitas com madeira, com colagem de fotografia de várias espécies de aves do Pantanal; e no outro lado da peça foi descrito o nome popular e científico das espécies. Assim, o encaixe do dominó, resultou do reconhecimento da ave através da fotografia e do nome popular e científico. 
7. Jogo de Mímica, no qual foram escolhidas fotografias de dez espécies de aves existentes no Pantanal com nome popular e científico colocados em tiras de papel e entregues aos alunos, os quais imitavam as aves de acordo com o observado em campo. Também houve a alternativa de eles mesmos escolherem o comportamento de uma ave e assim representá-la para adivinhação do grupo.

8. Jogo sobre o Canto das Aves. Os alunos foram distribuídos em grupos para que identificassem as aves ao ouvir o som reproduzido no computador.

9. Desenhos de aves para pintar, cujas espécies eram bastante conhecidas dos alunos. A pintura era livre seja com lápis de cor, tinta, giz de cera, bem como pinturas em tecido.

10. Jogo Trilha do Conhecimento (MAMEDE, 2003): proposta de jogo cooperativo, adaptado à temática aves e suas interações com o ambiente, buscando provocar reflexões, interação, reconhecimento da biodiversidade e valorização de vivências em ambiente natural.

Ao final do projeto, foi reaplicado o questionário semiestruturado, a fim de mensurar o aprendizado individual e coletivo dos alunos, o que resultou em análises qualitativas, e quantitativas dos dados por meio do teste de Wilcoxon, um teste não-paramétrico para a comparação de duas amostras pareadas, com maior utilidade em pesquisa educativa, sendo possível avaliar o impacto deste trabalho na vida escolar e cotidiana dos alunos.

\section{Resultados e discussão}

\section{Caracterização da avifauna da BEP/UFMS}

As aves ocorrentes na área da BEP baseiam-se principalmente em aves de mata ciliar, complementadas, sazonalmente, por espécies de outras unidades de paisagem adjacentes. Cada vivência em campo para observação de aves, com duração média de duas horas, resultava em pelo menos 40 espécies visualizadas, entre garças, corujas, tucanos, ariramba, arancuã, arapaçus, joão-de-barro, sabiás, sanhaços, bico-de-prata, trinca-ferro, cardeal, galo-dacampina, joão-pinto, chopim e outros passeriformes.

O comedouro para aves, a partir deste trabalho, tornou-se, espontaneamente, ponto de encontro para a observação das aves. Sempre que os alunos chegavam à escola, logo visitavam o comedouro e dividiam opiniões sobre quais espécies se faziam presentes, se era macho ou fêmea, filhote e quais os comportamentos adotados. Além de potencializar o papel social da escola, foi possível perceber como o interesse pelas aves foi sensivelmente ampliado ao longo do projeto. Segundo Alves (1980), o ato de ver não é algo natural e que, portanto, precisa ser aprendido. É natural que a 
visão de mundo, seja marcada pela prática cotidiana, sendo assim este trabalho aprimora por meio das atividades educativas em sala de aula o olhar para a natureza ao observar as aves em seu cotidiano.

\section{Abrangência do projeto}

De modo geral, o projeto teve reflexo positivo em todos os 20 alunos da escola rural Luiz de Albuquerque de Melo Pereira e Cáceres e extensões. No entanto, o foco principal concentrou-se em 11 alunos das últimas séries do ensino fundamental, cujo aprendizado foi devidamente avaliado ao longo do projeto. Para as análises quantitativas através dos questionários semiestruturados, apenas 07 compuseram a amostra, uma vez que o número de alunos matriculados na referida escola sofre constante alteração, em virtude, principalmente, da sazonalidade, da oferta de emprego às famílias, em sua maioria pescadores, sendo que alguns participaram ou só no início ou apenas no final do trabalho.

Gradativamente pode ser observado, junto aos alunos, após quase um ano do desenvolvimento do projeto, a construção do conhecimento, transformação, assim que iniciamos o processo dialógico de ensino, conscientização, sensibilização e autocrítica. Krasilchik (1988) afirma que educar para a cidadania, sem limitar a escola ao papel de preparação do indivíduo maleável e manipulável é o desafio que se enfrenta no ensino de ciências.

\section{Contação de estórias e aplicação de jogos educativos}

As estórias contadas, neste projeto, por um bem-te-vi - atento, curioso e muito comunicativo - mostraram as problemáticas ambientais enfrentadas localmente, bem como abordaram conteúdos de ciências da natureza no que se refere à classe das aves, todavia, sem pretensão doutrinária. Ao ouvir as estórias, os adolescentes passaram a visualizar de forma mais clara os problemas existentes na sua realidade local e social, discutindo e refletindo sobre suas causas, consequências e soluções, de forma descontraída sem, contudo, perder a seriedade (Figura 1). 


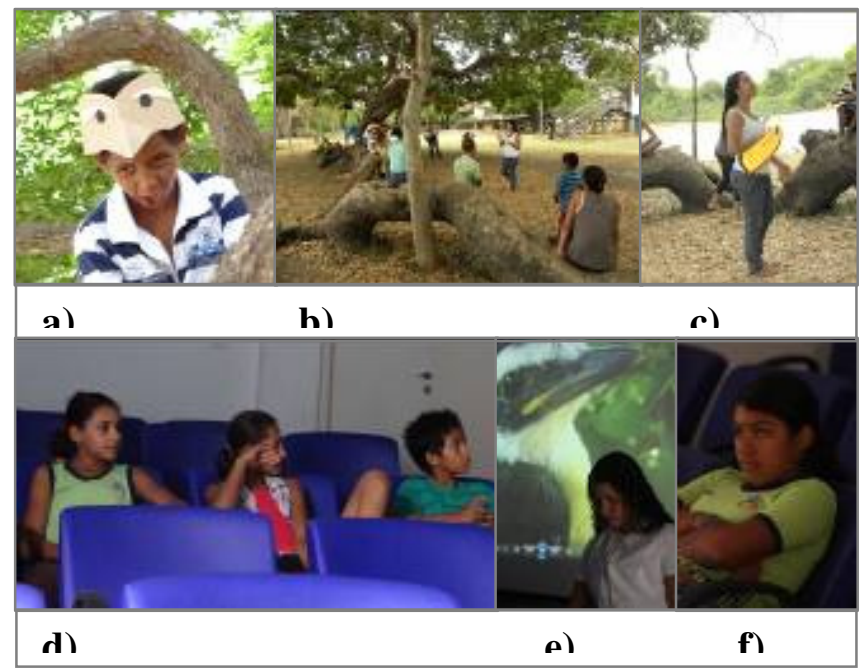

Figura 1: Contação de estórias nas formas teatral (a,b,c) e em sala de multimídia (d, e, f). BEP/UFMS, 2013. Fonte: Acervo de fotografias pessoal das autoras.

O lúdico no processo de ensino-aprendizagem, enquanto parte das atividades essenciais da dinâmica humana, pode constituir eficiente ferramenta para a construção do conhecimento, sendo uma forma eficaz de envolver os alunos nas atividades relacionadas ao conteúdo que se quer abordar. Assim, por meio de jogos, o conhecimento pode ser construído com prazer, alegria, entretenimento e apresenta resultados satisfatórios. Portanto, torna-se importante a utilização dos jogos, sendo da Memória, Encaixe, Dama, Velha, Dicas, Dominó, Mímica, Canto das aves, Trilha do conhecimento, ou desenhos para pintar, como instrumento metodológico no processo educacional. Logo, se trabalha a capacidade do aluno de expressar, analisar, criticar e transformar a realidade de forma reflexiva, no que diz respeito à reconstrução de valores, crenças, culturas, atitudes, comportamentos e disciplina. Além disso, permitem um processo de construção do sujeito com o meio e inter-relação entre pessoas, já que a educação é uma prática de interação e troca de saberes (FREIRE, 1996; SILVA et al., 2007). Na educação ambiental, os jogos serviram como complemento às estórias para que a mesma fosse exercitada com os alunos por diferentes práticas e linguagens, tornando esse processo efetivo ao relacionar saber e atitude (Figura 2).

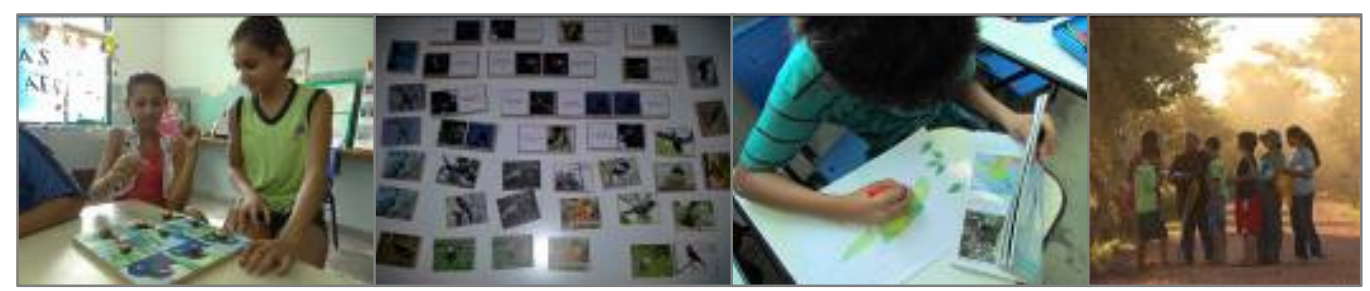

Figura 2: Desenvolvimento de jogos lúdicos (da esq. para a dir.: jogo da velha, jogo da memória e dominó, arte em desenhos e pinturas e Trilha do Conhecimento).

Fonte: Acervo de fotografias pessoal das autoras. 
Os Parâmetros Curriculares Nacionais reforçam esta ideia, ao considerar que, trabalhar de forma transversal significa buscar a transformação dos conceitos, a explicitação de valores e a inclusão de procedimentos, sempre vinculados à realidade cotidiana da sociedade, de forma a obter cidadãos mais participativos (BRASIL, 1997; 1998).

\section{Vivências em campo (observação de aves)}

Observação das aves não se traduz somente na forma científica, mas sim em uma forma de lazer para todas as pessoas de quaisquer idades, fornecendo um incentivo agradável de contato entre o ser humano e o ambiente natural, contribuindo para a proteção da fauna e aumento da qualidade de vida (SICK, 1997; ARGEL-DE-OLIVEIRA, 1997; SILVA; MAMEDE, 2008). A observação de aves incentiva ao maior interesse pela natureza, e, com a prática, são incorporadas atitudes importantes no processo de educação ambiental (FRISCH, 1981).

As saídas a campo para observação das aves com a utilização de equipamentos como luneta e binóculos, permitiram novas descobertas e curiosidades sobre o ambiente, possibilitando aos alunos, por exemplo, perceberem como a interação entre os seres se parece com o cotidiano humano, fazendo-se necessário sua observação criteriosa para melhor compreensão com vistas a conduzir a sociedade para ações mais harmoniosas com o meio. Além disso, praticavam matemática, relacionavam o que viam com a geografia e história, dentre outras formas de potencializar o conhecimento integrado, a autoestima e a valorização da biodiversidade. Após as saídas, os alunos retornavam à sala, plenos de aventuras a compartilhar com os colegas. $\mathrm{Na}$ sala de aula, realizavam busca por mais informações sobre as espécies observadas, com auxílio de guias de campo, e, em seguida faziam a verificação do número total de espécies observadas. Por meio de anotações em caderneta de campo descreveram informações sobre o comportamento, a morfologia das aves e quais espécies se encontravam no trajeto casa/escola e que até então, passavam despercebidas (Figura 3).

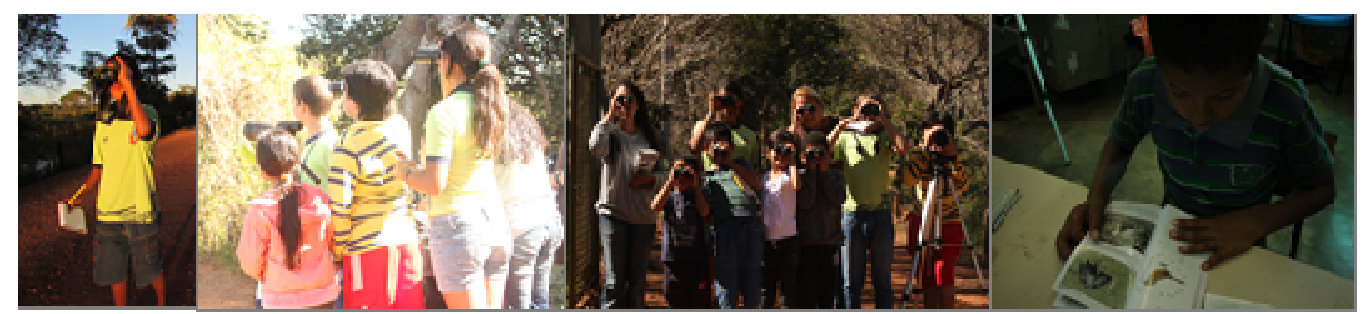

Figura 3: Saídas a campo para observação da diversidade de aves do Pantanal presente nas imediações da escola e conferimento da lista de espécies em sala de aula.

Fonte: Acervo de fotografias pessoal das autoras. 
Outro aspecto importante na observação das aves é ouvir e identificar os sons da natureza, incluindo os das aves. Assim, durante as vivências em campo, os alunos eram estimulados a ouvir e memorizar os sons emitidos pelas aves, as mais comuns do dia-a-dia. Para as aves, as manifestações sonoras são tão importantes quanto os aspectos morfológicos. A vocalização comunica parceiros para a reprodução, afirmam a territorialidade, bem como adverte sobre a presença de potencial predador no local, dentre outros aspectos (SICK, 1997). Para o humano, além das cores que provocam fascínio pelas aves, os sons por elas produzidos resgatam o ser à sua essência existencial, proporcionando satisfação e bem estar por estabelecer a conexão e a interação com a natureza. Mendonça e Neiman (2003) pontuam que o ambiente natural não deve ser abordado como a simples soma de elementos que compõem determinado espaço físico, chamado mata, floresta ou campo, mas essa interação deve estimular a compreensão da complexidade do mundo natural e os diferentes comportamentos e arranjos estruturais resultantes que, por sua vez, devem refletir na construção da sociedade e seus princípios éticos.

A cada retorno à BEP para as pesquisas e condução deste projeto, os alunos sempre tinham novidades a contar sobre as aves observadas e permaneciam ansiosos e eufóricos até relatarem cada experiência ou nova ave encontrada. Certamente que o percurso até a escola, o intervalo entre as aulas, o quintal de casa, os sons do Pantanal, a interação com a família e entre a professora, e os colegas nunca mais serão os mesmos a partir deste trabalho.

\section{Aprendizagem do ensino de ciências}

Após a aplicação de todas as atividades propostas observou-se o real aprimoramento quanto às percepções frente a algumas abordagens tanto de ciências, quanto do viver em sociedade, postura ética, respeito e demais práticas educativas importantes para a convivência harmônica com o ambiente, o qual, evidentemente, envolve a sociedade.

A presença de penas nas aves representa a característica mais marcante desse grupo biológico, no entanto, apenas $43 \%$ dos alunos lembraram dessa característica antes da implementação do projeto, enquanto que, no formulário final pós-intervenções, todos apontaram tal propriedade morfológica. Outras análises qualitativas estão apresentadas na Tabela 1.

Nota-se que os itens apontados são os comuns à realidade local. Houve maior detalhamento em todas as respostas do pós-intervenções. A importância e o desafio estão em se trabalhar o cotidiano tornando-o perceptível, ao mesmo tempo, interessante e instigante ao aprendizado. Sobre a importância das aves para a natureza, foi interessante perceber que as aves deixaram de ter apenas função utilitarista para o ser humano, tornando-se importantes a si próprias e para o ambiente natural, quando abordaram sobre reprodução e dispersão de sementes (por eles referido como reflorestamento). Seres 
humanos e demais seres vivos estão em parcerias que objetivam manter a capacidade de perpetuação de vida no planeta e esse enfoque é uma construção a ser instigada pela educação ambiental (GUIMARÃES, 2011).

Tabela 1: Análise qualitativa do aprendizado dos alunos mediante ao formulário, antes e depois as atividades desenvolvidas na pesquisa $(n=11)$.

\begin{tabular}{|c|c|c|}
\hline Abordagens & Antes & Depois \\
\hline $\begin{array}{l}\text { Biologia básica das Aves } \\
\text { quanto à alimentação }\end{array}$ & $\begin{array}{l}\text { frutos, plantas, animais e } \\
\text { iscas. }\end{array}$ & $\begin{array}{l}\text { Goiaba, acuri, bocaiúva, } \\
\text { jenipapo, manga, frutos de } \\
\text { sete-copas, ingá, flores de } \\
\text { piúva e de paratudo, insetos, } \\
\text { peixes como lambari, arroz e } \\
\text { outros. }\end{array}$ \\
\hline $\begin{array}{l}\text { Importância das aves para } \\
\text { a natureza }\end{array}$ & $\begin{array}{l}\text { Beleza, alegria, atração } \\
\text { turística. }\end{array}$ & $\begin{array}{l}\text { Beleza, alegria, cores, atração } \\
\text { turística, reprodução e } \\
\text { dispersão de sementes } \\
\text { (reflorestamento). }\end{array}$ \\
\hline $\begin{array}{l}\text { Atitudes para proteção das } \\
\text { aves }\end{array}$ & $\begin{array}{l}\text { Não desmatar, não queimar a } \\
\text { vegetação, não maltratar os } \\
\text { animais. }\end{array}$ & $\begin{array}{l}\text { Denunciar o tráfico de animais } \\
\text { silvestres, não descartar/jogar } \\
\text { lixo de forma inadequada no } \\
\text { ambiente, não desmatar, não } \\
\text { queimar as árvores, não } \\
\text { maltratar os animais, não } \\
\text { extrair filhotes de aves dos } \\
\text { ninhos e não prender as aves. }\end{array}$ \\
\hline
\end{tabular}

Fonte: Elaboração das autoras.

Com relação às formas de proteção das aves, na primeira avaliação relataram formas genéricas de proteção ao posto que, no segundo momento incluíram o combate ao tráfico de animais e à manutenção de aves presas em cativeiro. Para que tais ações sejam, de fato, aplicadas, trabalhos semelhantes a este precisam ser empreendidos de forma contínua para assegurar 0 cumprimento dessa vontade popular manifestada em favor da conservação ambiental.

$\mathrm{Na}$ Figura 4 se percebe que os alunos aumentaram significativamente seu nível de conhecimento sobre as espécies de aves existentes no local, havendo diferença estatisticamente significativa entre o número de espécies reconhecidas antes e depois das intervenções propostas por este trabalho (teste de Wilcoxon: $\mathrm{T}=0 ; \mathrm{P}=0,0189, \mathrm{n}=7$; nível de significância $5 \%$ ). Cumpre ressaltar, que os dados apresentados nesta figura representam apenas o número de espécies lembrado durante o preenchimento do formulário, não necessariamente o que eles passaram a conhecer a partir do projeto. 


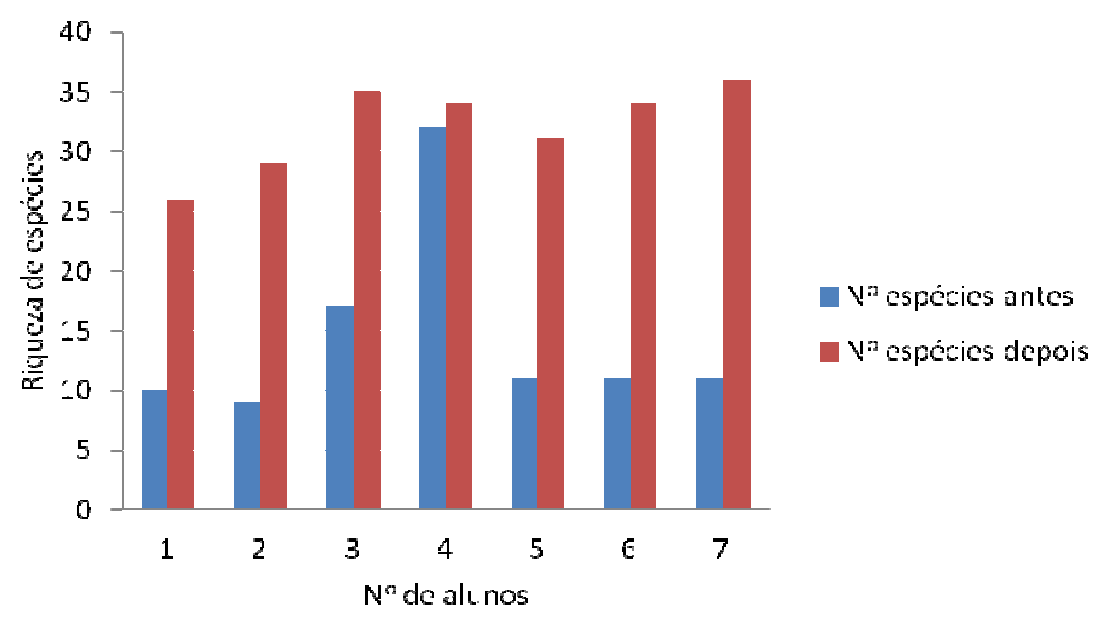

Figura 4: Análise quantitativa da riqueza de espécies mencionada pelos alunos antes e depois das atividades desenvolvidas. Fonte: Elaboração das autoras.

Além desses resultados, já conseguiam responder quais eram as aves aquáticas e terrestres bem como as de mata ciliar e de campo aberto com associação à alimentação e ao hábitat. As atividades serviram não apenas para memorizarem o nome das espécies, mas principalmente para reconhecer a riqueza de espécies ali presentes enquanto motivação para a adoção de novas atitudes para proteção ambiental, passo importante para mudanças na sociedade. Outro aspecto importante a ser ressaltado é que, pelo fato de o Pantanal apresentar alta riqueza e abundância de aves, a demanda de mão de obra para a condução de visitantes observadores de aves (birdwatcher) é consideravelmente alta e o aprendizado sobre a avifauna local pode representar oportunidade para formação e aprimoramento profissional da comunidade.

\section{Valores adquiridos e incorporados com ações de educação ambiental}

Analisados alguns aspectos relacionados à educação ambiental, pode ser observado a potencialização e/ou afirmação de alguns valores, tais como:

Respeito: com a aplicação dos jogos cooperativos, os alunos passaram a desenvolver comportamentos de respeito com o outro, com o professor, mediante as regras das brincadeiras.

Valorização do saber popular: a partir de conversas, jogos e estórias, os quais se relacionavam com o saber popular local, vários alunos contavam alguma estória que tinham ouvido em casa, muitas das quais relativas às lendas e mitos da região. Acredita-se que o resgate desses saberes seja importante para a valorização do identitário cultural local, afirmação da identidade histórico-cultural de cada cidadão e auto-estima, sendo importante deixá-los caminhar sobre seus conhecimentos pré-adquiridos, acrescentando 
apenas informações qualitativas, neste caso, sobre os ambientes que os rodeiam e a riqueza de espécies presentes.

Cidadania: os alunos passaram a exercitar cidadania quando precisaram cumprir deveres como sujeitos de um mesmo ambiente, demonstrando atitudes coerentes, refletindo sobre as decisões, mas também usufruindo de direitos como a qualidade do ambiente, da água, do ensino, do alimento, da saúde, dentre outros aspectos que remetem à qualidade de vida.

Alteridade: durante os jogos mostraram confiança, exercitaram a dependência do outro para a realização de várias atividades, interagiram entre si, demonstrando a necessidade de agir no coletivo, com companheirismo, união, mesmo nas conversas e na ajuda mútua para cumprirem determinada tarefa.

Entretenimento: diversão e aprendizado se misturaram durante o desenvolvimento das atividades. Alunos aprenderam brincando, interagindo com o professor e o colega, agregando afetividade, satisfação pessoal e coletiva, além de integração e disposição para a apreensão de conhecimento.

Respeito às diferenças: a percepção de que cada ser humano é diferente do outro, assim como cada ave o é, foi devidamente exercitada. O ser humano difere entre si em atitudes, fisicamente, mentalmente e culturalmente, e tais diferenças devem contribuir para melhor convivência entre a sociedade e desta com a natureza.

Socialização, interação e questionamentos: a partir dos diferentes jogos e brincadeiras aplicadas, vários alunos conquistaram maior auto-estima, tornando-se mais desinibidos e seguros para exporem suas ideias. Morin (2000) sugere que a educação instigue o aluno a interrogar-se a si mesmo, a sua condição humana, questionando primeiro sobre qual posição assumir não só localmente, mas também universalmente, e não em função do seu próprio ego, mas em função dos seres vivos como um todo.

\section{Conclusões}

O projeto aliou satisfatoriamente educação ambiental e ensino de ciências utilizando como instrumento didático-pedagógico a observação de aves e atividades lúdicas relacionadas, no Pantanal Sul, região conhecida como Passo do Lontra.

As estratégias adotadas como práticas educativas proporcionaram a sensibilização com a natureza e contribuíram para a formação cidadã. Os alunos passaram a obter novos hábitos, atitudes e ações educativas em defesa da qualidade do ambiente, respeito entre si e com o meio.

As estórias, jogos e saídas a campo desenvolveram a capacidade e habilidade de raciocínio e aprendizagem do ensino de ciências, permitindo a livre expressão, interação, pensamento crítico e novas ideias. Bem como 
despertaram o interesse pela natureza ao compreender tamanha diversidade tão próxima, antes porém despercebida. Assim, revelaram atitudes buscando soluções de conservação ao compreender sua posição frente aos desafios ambientais e sociais do contexto local.

O projeto permitiu a disseminação dos resultados de pesquisa produzidos na BEP por pesquisadores ornitólogos, oportunizando conhecimento à comunidade local.

Após o processo de ensino-aprendizagem, os alunos passaram a mostrar aos pais o que de novo aprenderam bem como suas curiosidades, melhorando também a interação entre pesquisadores, os alunos da escola e a população local.

Aulas expositivas, associadas ao lúdico e vivências em campo contribuíram para melhor aprendizagem dos alunos, traduzindo-se no comportamento, participação, postura reflexiva, investigativa, empoderamento, alteridade e autonomia para tomada de decisões, sendo alguns dos valores por eles desenvolvidos enquanto processos para a formação cidadã.

\section{Agradecimentos}

À Universidade Federal de Mato Grosso do Sul e ao INAU (Instituto Nacional de Ciência e Tecnologia em Áreas Úmidas), pelo subsídio em transporte, alimentação e estadia na Base de Estudos do Pantanal-BEP, onde se localiza a escola, área de estudo desta pesquisa.

Ao Instituto Mamede de Pesquisa Ambiental e Ecoturismo pelo empréstimo de equipamentos e doação de materiais didáticos, e à marcenaria Estilo e Design pela modelação e doação das madeiras e vidros para confecção dos jogos.

\section{Referências}

ALVES, M.A.S; SILVA, J.M.C; SLUYS, M.V; BERGALLO, H.G; ROCHA, C.F.D. A ornitologia no Brasil: pesquisa atual e perspectivas. 1. Ed. Rio de janeiro: EdUERJ, 2000.

ALVES, R. Conversas com quem gosta de ensinar. 1. Ed. São Paulo: Cortez editora, Autores associados, 1980.

AMORIM, A.C.R. Educação. In: FERRARO JÚNIOR, L.A. (Org.). Encontros e caminhos: Formação de educadoras (ES) ambientais e coletivos educadores. 1. Ed. Brasília: Ministério do meio ambiente e Diretoria de educação ambiental, 2005.

ARGEL-DE-OLIVEIRA, M.M. El uso de aves en Educación Ambiental. In: Encuentro Boliviano para la Conservación de las Aves, 3, Santa Cruz, 1996. Actas. Armonia, Bird Life, Santa Cruz de la Sierra, 1997. p. 27-30. 
BRASIL. Ministério da Educação. Diretrizes Curriculares Nacionais Gerais da Educação Básica. Brasília: MEC, SEB, DICEI, 2013.

BRASIL. Ministério da educação. Parâmetros curriculares nacionais: Ciências naturais. Brasília: MEC/SEF, 1998.

BRASIL. Presidência da República. Lei no 9.795 de 27 de abril de 1999: Política nacional da educação ambiental. Disponível em: < http://www.planalto.gov.br/ccivil 03/leis/19795.htm> Acesso em: 01 abr. 2014.

BRASIL. Secretaria de educação fundamental. Parâmetros curriculares nacionais: Apresentação dos temas transversais, ética. 1. Ed. Brasília: MEC/SEF, 1997.

CBRO. Comitê Brasileiro de Registros Ornitológicos (2014). Lista das aves do Brasil. $11 . \quad$ Ed. Disponível em: <http://www.cbro.org.br/CBRO/pdf/AvesBrasil2014.pdf> . Acesso em: $01 \mathrm{abr}$. 2014.

FREIRE, P. Educação e mudança. 12. Ed. São Paulo: Paz e Terra, 1981.

FREIRE, P. Pedagogia da autonomia: saberes necessários a prática educativa. 25. Ed. São Paulo: Paz e Terra, 1996.

FRISCH, J.D. Aves brasileiras. Volume I. São Paulo: Dalgas-Ecoltec Ecologia técnica, 1981.

GUIMARÃES, M. A dimensão ambiental na educação. 11. Ed. Campinas, SP: Papirus Editora, 2011.

KRASILCHIK, M. Ensino de ciências e a formação do cidadão. Revista Em Aberto, Brasília, ano 7, n. 40, p. 55-60, out./dez. 1988.

KRASILCHIK, M. Prática de ensino de biologia. 4. Ed. São Paulo: Editora da universidade de São Paulo, 2008.

MAMEDE, S.B. Interpretando a natureza: subsídios para a educação ambiental. 2. Ed. Campo Grande: UNIDERP, 2003.

MARINI, M.A; GARCIA, F.I. Conservação de aves no Brasil. Megadiversidade, v. 1, n. 1, p. 95-102, Julho. 2005.

MENDONÇA, R.; NEIMAN, Z. À sombra das árvores: transdisciplinaridade e Educação Ambiental em atividades extraclasse. Ed. São Paulo: Chronos, 2003.

MMA. Ministério do meio ambiente. Identidade da educação ambiental brasileira. Brasília: Ministério do meio ambiente, 2004.

MMA. Ministério do meio ambiente. Riqueza de espécies. Disponível em: $<$ http://www.mma.gov.br/biodiversidade/biodiversidade-brasileira>. Acesso em: 10 dez. 2013

MORIN, E. Os sete saberes necessários à educação do futuro. 2. Ed. São Paulo: Cortez ; Brasília, DF : UNESCO, 2000. 
NUNES, A.P. Estado de conservação da avifauna ameaçada de extinção ocorrente no Pantanal, Brasil. Atualidades ornitológicas On-line, n. 157, p. 85-98, set./out. 2010.

NUNES, A.P. Quantas espécies de aves ocorrem no Pantanal brasileiro?. Atualidades ornitológicas On-line, n. 160, p. 45-54, mar./abr. 2011.

POUGH, F.H.; JANIS, C.M.; HEISER, J.B. A vida dos vertebrados. 4. Ed. São Paulo: Atheneu Editora, 2008.

SATO, M.; CARVALHO, I.C.M. Educação ambiental: pesquisa e desafios. 1. Ed. Porto Alegre: Artmed, 2005.

SICK, H. Ornitologia Brasileira. 1. Ed. Rio de Janeiro: Nova Fronteira, 1997.

SILVA, A.M.T.B.; METTRAU, M.B.; BARRETO, M.S.L. O lúdico no processo de ensino-aprendizagem das ciências. Revista brasileira de Estudos pedagógicos, Brasília, v. 88, n. 220, p. 445-458, set./dez. 2007.

SILVA, M.B.; MAMEDE, S.B. Mamíferos e aves como instrumentos de educação e conservação ambiental em corredores de biodiversidade do cerrado, Brasil. Mastozoología Neotropical, Mendoza, p. 261-271, dez./mar. 2008. 